\title{
APLIKASI PENJADWALAN KOAS DENGAN METODE BRANCH AND BOUND
}

\author{
Pulut Suryati $^{1)}$, Deborah Kurniawati ${ }^{2}$ \\ ${ }^{1,2)}$ Program Studi Sistem Informasi STMIK AKAKOM \\ e-mail: lut_surya@akakom.ac.id ${ }^{1)}$,debbie_mom_rai@akakom.ac.id ${ }^{2)}$
}

\begin{abstract}
ABSTRAK
Program kepaniteraan klinik merupakan suatu bagian penting dalam sistem pendidikan kedokteran. Program kepaniteraan klinik yaitu suatu periode pendidikan kedokteran yang ditekankan pada penerapan teori-teori yang sebelumnya sudah di dapat dari periode pra klinik. Program kepaniteraan klinik dilaksanakan di rumah sakit atau pun puskesmas yang ditunjuk. Para calon dokter yang sedang melaksanakan program ini sering di sebut dengan istilah koas. Penjadwalan koas yaitu pengaturan dari beberapa koas yang akan dialokasikan pada beberapa unit dalam waktu atau periode tertentu. Hal ini bukan merupakan pekerjaan yang mudah. Penelitian ini mengusulkan rancang bangun aplikasi penjadwalan koas sebagai permasalahan integer programming dan kemudian diselesaikan dengan metode branch and bound. Permasalahan meliputi fungsi tujuan yaitu meminimalkan pelanggaran konstrain sebagai biaya pinalti dan fungsi kendala. Banyaknya jumlah variabel dalam proses penjadwalan koas dipengaruhi oleh lama periode, jumlah unit dan banyaknya kelompok yang diinputkan atau terlibat dalam proses penjadwalan. Hasil dari pengujian menunjukkan bahwa aplikasi yang dibangun dapat menghasilkan jadwal bagi koas.
\end{abstract}

Kata Kunci: penjadwalan, branch and bound, integer programming

\begin{abstract}
"Kepaniteraan klinik" program is an important part of the medical education system. "Paniteraan clinic" program is a medical education period emphasizing on the application of previous theories obtained from pre-clinic period. This program is conducted in hospitals or in pointed health centers. Doctor candidates conducting this program are often called trainee. The trainee scheduling is a set of management for some trainees allocated to some units in a certain period which is not an easy job. This reseach proposes a trainee scheduling aplications using branch and bound method. This problem consists of objective function that is to minimize violation constraint as a total penalty cost and constraints function. Number of variabel on scheduling proses depend on periode, number of units and number of groups. The test result showed that this application can give solution of trainee scheduling problem.
\end{abstract}

Keywords: branch and bound, integer programming, scheduling

\section{PENDAHULUAN}

$\mathrm{P}$ rogram kepaniteraan klinik merupakan suatu bagian penting dalam sistem pendidikan kedokteran. Program kepaniteraan klinik yaitu suatu periode pendidikan kedokteran yang ditekankan pada penerapan implementasi teori-teori yang sebelumnya sudah di dapat dari periode pra klinik. Praklinik adalah menjalani kuliah-kuliah selama 3,5 tahun - 4 tahun. Program kepaniteraan klinik dilaksanakan di rumah sakit atau pun puskesmas yang ditunjuk, para calon dokter yang sedang melaksanakan program ini sering di sebut dengan istilah koas (trainee/clerkship/physicians) (dari kata ko-asisten, artinya sebagai asisten dokter). Pada program panitera klinik akan disusun jadwal para koas untuk mengikuti sejumlah aktifitas di unit di rumah sakit yang ditunjuk untuk satu periode yang telah ditentukan. Program ini juga menjadi bagian untuk pemenuhan sumber daya di rumah sakit atau klinik [1], [2]. Belien dan Demeulemester [3] menggunakan pemodelan integer linear programming untuk penyelesaian masalah penjadwalan koas.

Penjadwalan koas di Fakultas Kedokteran Universitas Gadjah Mada yang ditempatkan di RS. Dr. Sardjito saat ini, penjadwal mempunyai 7 pola urutan aktifitas penjadwalan koas. Beberapa group koas dijadwalkan dengan mengikuti 1 pola untuk tiap group (trail and error). Setelah berhasil membuat jadwal suatu group dan ketika group yang lain tidak dapat dijadwalkan tanpa melanggar beberapa batasan, penjadwal akan menyusun ulang group sebelumnya untuk melihat kemungkinan perbaikan dengan mempertimbangkan batasan yang tidak boleh dilanggar, selain batasan kapasitas, batasan kebutuhan formasi (formation requirements), non availability constraints dan setup constraints terdapat juga batasan untuk aktivitas serta libur yang berturut-turut. Permasalahan yang diusulkan pada artikel ini adalah bagaimana membangun aplikasi dengan yang mengimplementasi pemodelan integer programming untuk penyusunan jadwal menggunakan algoritma branch and bound.

Penggunaan integer linear programming (ILP) untuk memodelkan masalah penjadwalan koas yang bertujuan untuk meminimalkan biaya pinalti. Dibandingkan dengan penjadwalan perawat (Nurse Scheduling Problem $N S P$ ) masalah penjadwalan koas ini lebih rumit [1]. Pertama karena masalah penjadwalan koas biasanya berlaku untuk periode yang lebih lama dibanding NSP sehingga jumlah dari variabel akan bertambah. Kedua, koas masih harus menyelesaikan pendidikanya, sehingga mereka harus menyelesaikan beberapa activity dimana kapasitas tiap 
activity tersebut biasanya terbatas. Hal ini akan menambah jumlah variabel dan constraint. Ketiga, tidak seperti NSP sebuah activity untuk koas tidak dapat dibagi dengan activity lain atau dengan waktu libur. Koas juga tidak dapat diganti dengan koas lain jika ia tidak dapat melaksanakan activity tersebut. Kondisi ini akan menambah beberapa konstrain yang komplek didalam pemodelan. Pada penelitian ini akan digunakan metode branch and bound yang digunakan untuk menyelesaikan masalah penjadwalan koas, yang kemudian dari permasalahan implementasinya ke dalam sistem. Branch and bound merupakan salah satu metode penyelesaian masalah integer programming.

Berdasarkan latar belakang yang telah diuraikan, dapat dirumuskan suatu masalah bagaimana aplikasi untuk masalah penjadwalan koas dalam integer programming dengan penyelesaian menggunakan metode branch and bound. Tujuan dari penelitian ini adalah untuk menerapkan metode branch and bound sebagai algoritma penyelesaian masalah penjadwalan koas. Penelitian tentang aplikasi penjadwalan koas dengan metode branch and bound diharapkan dapat memberikan manfaat berupa alternatif solusi penjadwalan koas sehingga dapat memberikan kemudahan pada pihak koas maupun pihak rumah sakit.

Pemrograman Linear (Linear Programming) adalah salah satu model Operations Research yang menggunakan teknik optimisasi matematika linear di mana seluruh fungsi harus berupa fungsi matematika linear. Menurut Subagyo [4] Pemrograman linear merupakan suatu model umum yang dapat digunakan dalam pemecahan masalah sumber daya yang jumlahnya terbatas agar dapat dialokasikan secara optimal. Merupakan sebuah model yang dapat memecahkan masalah yang timbul apabila orang diharuskan untuk memilih atau menentukan setiap kegiatan yang akan dilakukan, dimana masing-masing kegiatan membutuhkan sumber yang sama sedangkan jumlahnya terbatas Salah satu metode penyelesaian masalah linear programming menggunakan algoritma branch and bound. Penelitian ini akan membahas mengenai penyelesaian masalah integer programming menggunakan algoritma tersebut yaitu algoritma branch and bound.

Hariadi [5] menggunakan algoritma branch and bound untuk pencarian solusi pemrograman non linear. Pemrograman nonlinier adalah satu bagian penting dari permasalahan optimasi, baik dari sudut pandang matematis maupun aplikasi. Banyak permasalahan dunia nyata yang dapat direpresentasikan ke dalam bentuk permasalahan pemrograman non linier. Dalam pemrograman nonlinier diperlukan metode untuk mencari nilai optimal global agar tidak terjebak pada pencapaian nilai optimal local. Pada makalahnya algoritma branch and bound diaplikasikan melalui proses relaxation pada permasalahan untuk mendapatkan solusi optimal global. Agar pertumbuhan jumlah sub permasalahan dapat dikendalikan maka kami memanfaatkan reformulasi kondisi (Karush-Kuhn Tucker) KKT. Uji coba dilakukan dengan menggunakan permasalahan pemrograman kuadratik. Dari percobaan yang dilakukan menunjukkan bahwa pembatasan sub permasalahan melalui reformulasi KKT sangat membantu pencapaian solusi optimal dengan algortima branch and bound.

Selain itu Kalczynski [6] dalam makalahnya didiskripsikan algoritma branch and bround untuk penyelesaian masalah Travel Salesman Problem (TSP) dengan asymmetric cost matrix (ATSP) yang diimplementasikan dengan Java. Penyelesaian masalah minimasi dengan BnB diusulkan untuk percobaan komputasi ATSP dan matrik biaya random yang diberikan dengan beberapa ukuran masalah $((50,100,150,200,250$ dan 300 kota). Untuk ukuran terbesar yaitu 300 kota masih dapat diselesaikan dengan implementasi yang diusulkan

Indriani dkk [7] menuliskan dalam makalahnya mengenai pendekatan branch and bound secara breadth fist (BFS) dan depth first (DFS). Dibahas mengenai kelebihan masing-masing dari dua metode dalam penelusuran yang digunakan. Algoritma branch and bound merupakan metode pencarian solusi di dalam ruang solusi secara sistematis yang diimplementasikan ke dalam suatu pohon ruang status dinamis. Setiap status tersebut diberikan biaya (cost) dalam pencapaian solusi, semakin kecil cost maka semakin cepat solusi ditemukan. Algoritma branch and bound membuat apenyelesaian masalah menggunakan algoritma ini lebih mangkus dibandingkan Brute Forse, khususnya untuk permasalahan kombinatotial seperti Travelling Salesperson Problem (TSP), Quadratic Assignment Problem (QAP) dan Job Shop Schedulling Problem. Dari dua metode penelusuran yang digunakan BFS membangkitkan seluruh anak yang mungkin dari suatu simpul dan memilih cost yang terbaik. Cara ini memberi kelebihan dalam menghemat waktu. Karena ini telah memikirkan masak-masak akan langkah yang ia ambil. Namun metode ini lebih menghabiskan memori (ruang status). Sedangkan DFS lebih ke arah untunguntungan. Jika solusi merupakan turunan dari anak pertama, maka metode ini akan sangat menghemat memori dan waktu, namun jika solusi terletk pada turunan anak terakhir, maka metode ini selain menghabiskan memori juga akan menghabiskan waktu.

\section{METODE}

Bahan penelitian diambil dari sumber data primer dan sekunder. Data primer diteliti secara langsung dari wawancara dan observasi di lapangan, antara lain :

1) Unit - data unit diperoleh atribut untuk disimpan dalam kelas unit meliputi nama unit, kapasitas, durasi pelaksanaan serta warna yang digunakan untuk mewakili unit yang akan ditampilkan dijadwal. 
2) Kelompok - data kelompok diperoleh atribut untuk kelompok yaitu nama kelompok dan jumlah anggota mahasiswa perkelompok.

3) Mahasiswa - data mahasiswa diperoleh atribut untuk mahasiswa yaitu nama, nomor mahasiswa dan jenis kelamin.

4) Jadwal - data jadwal diperoleh atribut untuk jadwal yaitu jumlah unit, jumlah kelompok, lama training dan tanggal mulai training.

Kebutuhan jadwal yang akan dibuat meliputi jadwal koas secara umum, jadwal koas per unit, jadwal koas per kelompok.

\section{A. Analisis dan perancangan Model}

Sistem dalam penelitian ini akan dibuat yaitu sistem penjadwalan untuk program panitera klinik atau biasa disebut dengan koas dengan mengunakan model matematika programing yaitu berupa integer linear programming yang diselesaikan dengan menggunakan metode branch and bound. Dalam sistem ini diharapkan dapat memenuhi batasan keras atau aturan yang telah ditetapkan baik dari Fakultas kedokteran maupun pihak mitra yaitu rumah sakit terkait dan dapat meminimalkan pelanggaran terhadap konstrain lunak.

Koas melaksanakan program panitera klinik dirumah sakit DR. Sardjito kurang lebih selama 85 minggu, dimana para koas dibagi dalam kelompok. Satuan waktu dihitung dalam satuan minggu. Periode pelaksanaan dimasingmasing unit telah ditetapkan. Selain periode pelaksanaan telah ditentukan aturan untuk jeda antar kedatang koas pada satu bagian dengan koas berikutnya. Setiap koas berhak untuk memperoleh libur setelah melaksanakan program koas pada 3 unit berturut-turut, koas memperoleh libur.

\section{B. Model Matematika}

Pengembangan model berupakan salah satu tahap penting dalam proses penjadwalan. Dalam tahap ini mengidentifikasi permasalahan yang dirumuskan dalam binary integer programming yaitu menentukan variabel keputusan, fungsi kendala, koefisien fungsi kendala dan relasi yaitu tanda batasan pada masing-masing fungsi kendala dan ruas kanan fungsi kendala. Beberapa kendala yang digunakan dalam memodelkan fungsi kendala pada penelitian ini meliputi

1) Kapasitas : Kendala kapasitas yaitu banyaknya kelompok koas yang dapat melaksanakan aktivitas pada suatu unit dalam satu periode. Kendala ini memiliki tanda " $\leq$ ".

2) Durasi training : Durasi training yaitu jumlah periode training yang harus dilaksanakan koas pada satu aktivitas atau satu unit bagian.

3) Tidak boleh lebih dari 2 aktivitas tiap periode : Kendala ini menunjukkan bahwa tiap koas tidak dapat melakukan lebih dari satu aktivitas pada periode yang sama.

4) Setup : Kendala setup yaitu untuk mengatur bahwa koas harus menjalan suatu aktivitas dalam satu waktu atau aktivitas dilaksanakan tanpa jeda suatu aktivitas lain atau suatu libur.

5) Jumlah maksimal aktivitas berturut-turut : Koas membutuhkan waktu untuk istirahat atau libur. Oleh karena itu, jumlah aktivitas berturut-turut dibatasi. Kendala ini merupakan soft constraint.

6) Jumlah maksimal libur berturut-turut : Libur yang terlalu lama juga dapat memberikan dampak yang tidak baik. Oleh karena itu, Jumlah periode libur berturut-turut dibatasi.

Beberapa notasi matematika digunakan dalam memodelkan permasalah penjadwalan pada penelitian ini yaitu :

Variabel:

1) Sebuah variabel keputusan untuk mendefinisikan waktu mulai suatu kelompok pada suatu aktivias:

$x_{i j k}\left\{\begin{array}{l}=1 \text {, Jika selama periode } 1 i \text {, kelompok koas } j \text { dijadwalkan untuk melaksanakan aktifitas di unit } k \\ =0 \text {, yang lain. }\end{array}\right.$

2) Sebuah variabel dummy untuk mendefinisikan waktu mulai suatu kelompok pada suatu aktivias:

$y_{i j k}\left\{\begin{array}{l}=1, \text { Jika selama periode } i, \text { kelompok koas } j \text { memulai aktivitas } k . \\ =0, \quad \text { yang lain. }\end{array}\right.$

3) Variabel Penalti:

$P_{i j}\left\{\begin{array}{l}=1, \text { Jika kelompok koas } j \text { dijadwalkan lebih dari maxA periode pada periode } i . \\ =0, \text { yang lain. }\end{array}\right.$

Indek dan Koefisien:

$i=$ indek dari periode $(1 \ldots n)$.

$j=$ indek dari kelompok $(1 \ldots m)$.

$k=$ indek dari aktivitas/unit/post (1 ...p).

1) Untuk kendala kapasitas:

Cap $_{i k}=$ Kapasitas dari aktivitas $k$ pada periode $i$.

2) Untuk kendala durasi training:

$D_{k} \quad=$ durasi /jumlah periode suatu kelompok untuk melaksanakan suatu aktivitas $k$.

3) Untuk jumlah maksimum libur berturut-turut: 
$\operatorname{maxH}=$ Jumlah maksimum libur berturut-turut.

4) Untuk jumlah aktivitas berturut-turut:

$\max A=$ Jumlah aktivitas berturut-turut.

Fungsi Tujuan:

$\operatorname{Min} \sum_{i=1}^{n} \sum_{j=1}^{m} P_{i j} X_{i j k}$

$P_{i j}$ merupakan biaya pinalti untuk penugasan kelompok koas $j$ pada periode $i$.

Fungsi Kendala:

1) Kendala kapasitas: Banyaknya kelompok koas yang dapat melaksanakan aktivitas pada suatu unit dalam satu periode. Pada periode $i$, kelompok koas $j$ dijadwalkan untuk melaksanakan aktifitas di unit $k$ dimana jumlah koas yang dijadwalkan dari $\mathrm{j}=1$ sampai dengan $m$ lebih kecil atau sama dengan kapasitas dari unit $\mathrm{k}$.

$$
\sum_{j=1}^{m} x_{i j k} \leq \max \left(0, \operatorname{Cap}_{i k}-\sum_{\mathbb{l}=i-D k+1}^{i}{ }_{i} l d_{i k}\right) \quad \forall i=1 . . n \text { dan } \forall k=1 . . p
$$

2) Durasi Training: Pada periode $i$, kelompok koas $j$ dijadwalkan untuk melaksanakan aktifitas di unit $k$ dimana jumlah pelaksanaan dari periode untuk $i=1$ sampai dengan $n$ sama dengan durasi periode suatu kelompok untuk melaksanakan suatu aktivitas $k$.

$$
\sum_{i=1}^{n} x_{i j k}=D_{k} \quad \forall j=1 . . m \text { dan } \forall k=1 . . p
$$

3) Tidak lebih dari satu aktivitas tiap periode untuk setiap group: Jumlah aktivitas pada periode $i$, kelompok koas $j$ lebih kecil sama dengan 1 untuk dijadwalkan melaksanakan aktifitas di unit $k$.

$$
\sum_{k=1}^{p} x_{i j k} \leq 1 \quad \forall j=1 . . m \text { and } \forall i=1 . . n
$$

4) Kendala setup: $y_{i j k}$ adalah setup atau dummy variabel. Tiap-tiap koas harus menjalan suatu aktivitas dalam satu waktu atau aktivitas dilaksanakan tanpa jeda suatu aktivitas lain atau suatu libur.

$$
\begin{array}{ll}
y_{1 j k}=x_{1 j k} & \forall j=1 . . m \text { dan } \forall k=1 \times p \\
y_{i j k} \geq x_{i j k}-x_{(i-1) j k} & \forall i=2 . . n ; \forall j=1 . . m \text { dan } \forall k=1 . \times p \\
\sum_{i=1}^{n} y_{i j k}=1 & \forall j=1 . . m \text { dan } \forall k=1 \times p
\end{array}
$$

5) Jumlah Maksimal aktivitas berturut-turut: Koas membutuhkan waktu untuk istirahat atau libur. Oleh karena itu, jumlah aktivitas berturut-turut dibatasi. Kendala ini merupakan soft constraint.

$$
\sum_{k=1}^{p} \sum_{i=i-\max A}^{i} x_{i j k}-p_{i j} \leq \max A \quad \forall i=\max A+1 . . n d a n \forall j=1 . . m
$$

6) Jumlah Maksimal libur berturut-turut: Libur yang terlalu lama juga dapat memberikan dampak yang tidak baik. Oleh karena itu, jumlah periode libur berturut-turut dibatasi.

$$
\sum_{k=1}^{p} \sum_{i=1-\max H+1}^{i} x_{i j k} \geq 1 \quad \forall i=\operatorname{maxH} . . n \text { and } \forall j=1 . . m
$$

\section{HASIL}

Pada bagian ini akan diuraikan pengujian sistem berkaitan dengan penyusuan jadwal koas dengan menggunakan metode branch and bound. Dilakukan pengujian terhadap variabel yaitu periode, kelompok dan unit. Berdasarkan data yang telah dimasukan dalam tiap-tiap id jadwal, maka sistem akan mengolah data sehingga diperoleh jadwal yang tidak melanggar konstrain yang telah ditentukan pada model yang dihasilkan. Untuk Pengujian data dengan data jumlah kelompok koas 2, jumlah unit 2 dan periode 8 minggu. Hasil pengujian menunjukkan waktu komputasi sebesar 0.1404 detik dengan jumlah variabel; 60, kontrain sebanyak 78 dan matrik solusi. Dari hasil matrik solusi kemudian disimpan dalam database untuk dapat diolah sehingga dapat dihasilkan jadwal koas. Dari proses penyusunan jadwal, matrik solusi yang dihasilkan selanjutnya ditampilkan dalam bentuk jadwal. Jadwal yang dihasilkan ditampil seperti pada Gambar 1. Dari hasil jadwal yang diperoleh, tidak terdapat kelompok koas yang dijadwalkan lebih dari 1 aktivitas dalam 1 waktu, setiap durasi dari tiap aktivitas dilaksanakan secara berturut-turut dimulai dari 1 periode. 


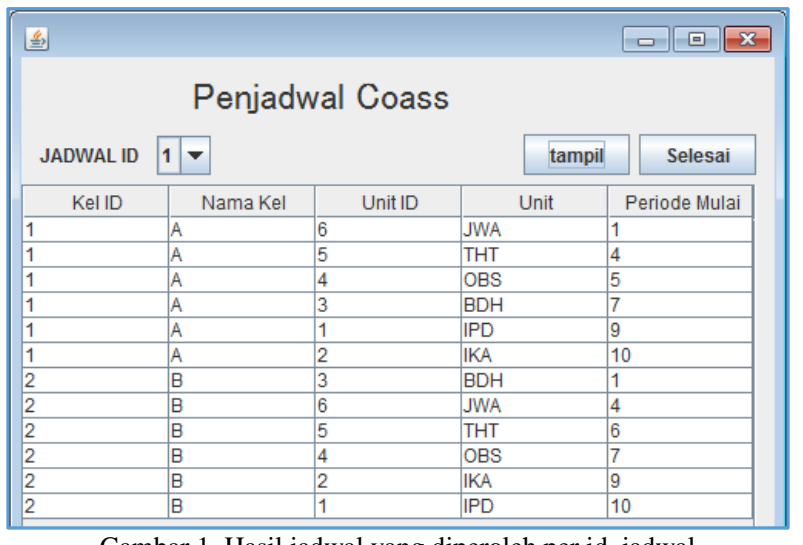

Gambar 1. Hasil jadwal yang diperoleh per id_jadwal

Gambar 2. menampilkan jadwal per unit, laporan ini digunakan untuk mempermudah pengecekan data untuk tiap unitnya sehingga dapat diketahui jika terdapat pelanggaran konstrain seperti kapasitas unit atau aktivitas yang berturut-turut dari jadwal yang dihasilkan.

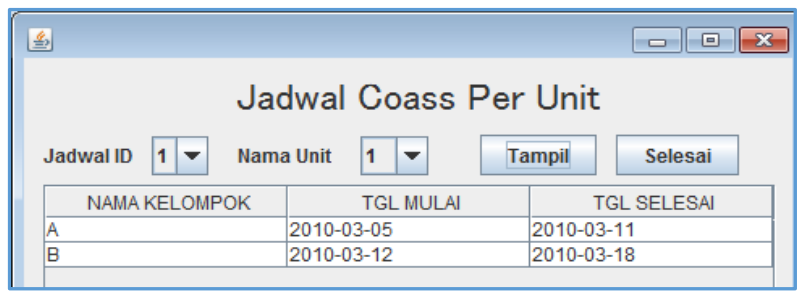

Gambar 2. Jadwal koas per unit

Gambar 3. merupakan jadwal per kelompok atau group koas, jadwal ini memudah dalam mengecek apakah suatu kelompok koas dijadwalkan lebih dari satu unit pada satu waktu, selain itu juga terdapat konstrain libur yang berturut-turut. Laporan ini menunjukkan bahwa jadwal yang dihasilkan tidak terdapat pelanggaran konstrain yang telah ditentukan atau jadwal optimal.

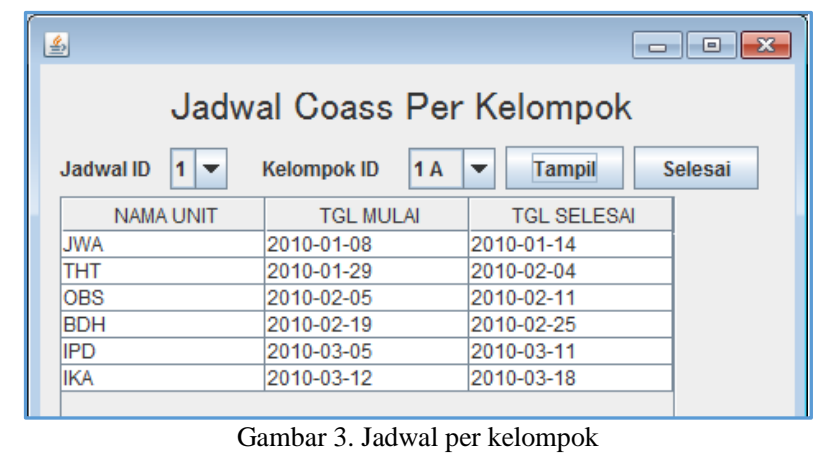

Informasi proses penyusunan jadwal digunakan untuk memperoleh ringkasan jumlah periode, unit, kelompok, waktu yang dibutuhkan dalam proses penyusunan, jumlah variabel dan konstrain serta informasi mengenai solusi yang dihasilkan, apakah dapat diperoleh jadwal yang optimal. Informasi ini ditunjukkan pada Gambar 4.

\section{PEMBAHASAN}

Dari hasil pengujian yang telah dilakukan, jadwal yang dihasilkan tidak terjadi pelanggaran konstrain yang telah ditentukan. Sehingga metode branch and bound yang digunakan baik untuk menyelesaikan masalah optimasi penjadwalan koas. Dari hasil pengujian yang telah dilakukan, jadwal yang dihasilkan tidak terjadi pelanggaran konstrain yang telah ditentukan. Sehingga metode branch and bound yang digunakan baik untuk menyelesaikan masalah optimasi penjadwalan koas.

Pada bagian ini akan diuraikan pengujian sistem berkaitan dengan penyusunan jadwal koas dengan menggunakan metode branch and bound. Dilakukan pengujian terhadap variabel yaitu periode, kelompok dan unit. Data diinputkan untuk berbagai perubahan variabel dengan pengujian dengan beberapa perubahan parameter variabel. Gambar 5. Grafik penambahan periode menunjukkan pengaruh perubahan periode terhadap jumlah variabel dan jumlah konstrain pada pembentukan model dari penyusunan masalah. Banyaknya jumlah kontrain dan jumlah variabel yang dibutuhkan tersebut juga akan berpengaruh pada penyelesaian permasalahan. 


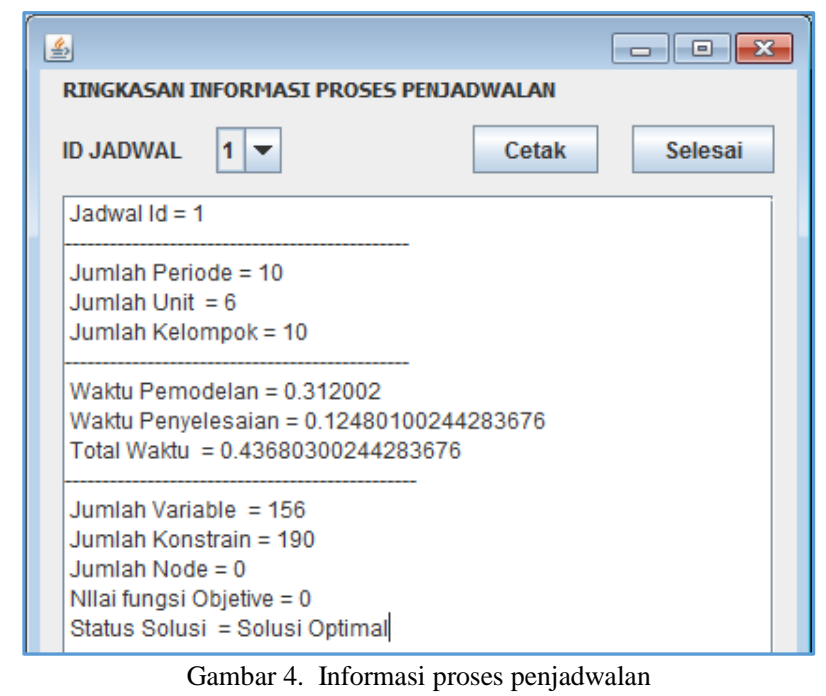

Gambar 6. Grafik penambahan unit menunjukkan pengaruh perubahan unit terhadap jumlah variabel dan jumlah konstrain pada pembentukan model dari penyusunan masalah. Selain periode, penambahan unit juga mempengaruhi banyaknya variabel dan kontrain dalam pemodelan integer programming.
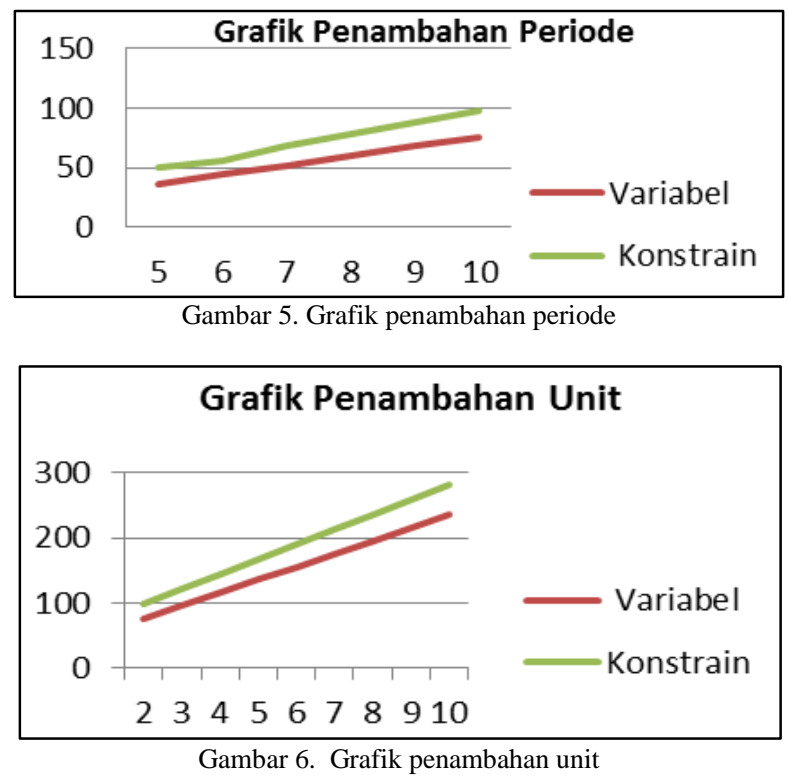

Gambar 7. Grafik penambahan kelompok menunjukan pengaruh perubahan kelompok terhadap jumlah variabel dan jumlah konstrain pada pembentukan model dari penyusunan masalah.

Hasil grafik menunjukan bahwa masing-masing variabel yaitu periode, unit dan kelompok sangat mempengaruhi jumlah variabel yang terbentuk, sehingga hal ini juga berpengaruh terhadap model integer programming yang dihasilkan. Banyaknya variabel dalam pemodelan integer programing akan berpengaruh pada waktu penyelesaian permasalahan dengan menggunakan algoritma yang digunakan yaitu branch and bound. Waktu penyelesaian yang relevan berpengaruh pada perolehan solusi optimal. Pada kasus penjadwalan koas fakultas kedokteran Universitas Gajah Mada, periode pelaksanaan program panitera klinik dikerjakan selama 85 minggu dengan terdiri dari 8 kelompok koas dan dilaksanakan pada 12 unit aktifitas. Pengujian dibatasi waktu 8 jam dan aplikasi belum dapat menghasilkan jadwal.

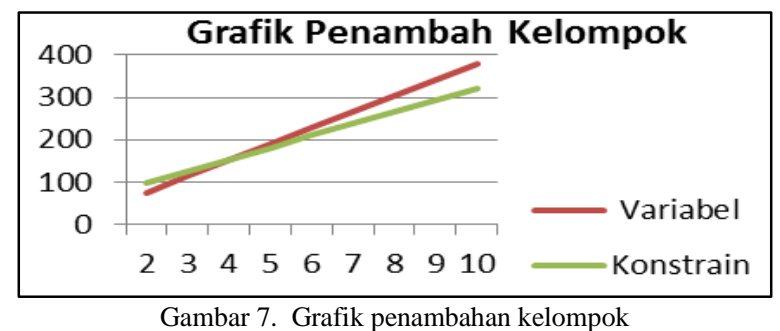




\section{SIMPULAN DAN SARAN}

Berdasarkan pembahasan bab-bab sebelumnya maka diambil kesimpulan adalah aplikasi penjadwalan koas dengan metode brand and bound yang dibangun dapat digunakan untuk penjadwalan koas. Banyaknya jumlah variabel dalam proses penjadwalan koas dipengaruhi oleh lama periode, jumlah unit dan banyaknya kelompok yang diinputkan atau terlibat dalam proses penjadwalan, hal ini juga berpengaruh pada waktu penyelesaian. Pada pengujian kasus nyata dengan batas waktu 8 jam aplikasi belum mampu menhasilkan jadwal.

Berdasarkan pada pengujian yang telah dilakukan sistem yang dibuat, masih banyak kekurangan dan kelemahan sehingga perlu dikembangkan lagi agar kinerjanya lebih baik, oleh karena itu saran yang diberikan adalah Penelitian selanjutnya dapat diusulkan pemodelan yang lebih efektif untuk masalah penjadwalan koas.

\section{REFERENSI}

[1] Belien,J., 2006, Exact and Heuristic Methologies for Scheduling in Hospitals: Problem, Formulation and Algorithms, Tesis, Faculteit Economische En Toegepaste Economische Weteschappen, Katholieke Universiteit Leuven, Belgium

[2] Amar, S., Dharma, I.G.B.B., 2011, Trainee Scheduling At Hospital: A Paper Review, SeNTI-UGM 2011: Synergy For Sustainability, B-071, Yogyakarta.

[3] Belien, J., Demeulemeester, E., 2004, Scheduling Trainees at a Hospital Department Using a Branch-And-Price Approach, Research Report OR 0403, Katholieke Universiteit Leuven, Department of Applied Economics.

[4] Subagyo, P. (2000). Dasar-Dasar Operation Research, BPFE-Yogyakarta

[5] Hariadi,V., 2009, Pencarian Solusi Pemrograman Non Linear Menggunakan Algoritma Branch and Bound, SNATI 2009, Yogyakarta.

[6] Kalczynski, 2005, A Java Implementation of the Branch and Bound Algorithm: The Asymmetric Traveling Salesman Problem, Journal Of Object Technology online at http://www.jot.fm, Vol. 4, No. 1, January-February 2005

[7] Indriani, R.F., Armyta, D., Safrina R, 2005, Pendekatan Branch and Bound Secara Breadth First dan Depth First, Departemen Teknik Informatika, Institus Teknologi Bandung.

[8] Hillier, F.S., Lieberman, G. J., 2005. Introduction Operations Research $8^{\text {th }}$ Edition, The McGraw-Hill Company, Inc.

[9] Purnowo, Y, 2007. Sistem Pendukung Pembuat Keputusan untuk optimasi penggunaan lahan-bangunan real estate menggunakan pemrograman linear - Simplex, Tesis, Fakultas Ilmu Komputer UGM, Indonesia.

[10] Penido, M.L., 2004. Planning and Scheduling in Manufacturing and Services, Springer, USA.

[11] Putra,D.M.D.U., 2011. Penerapan Algoritma Genetika untuk menyelesaikan permasalahan penjadwalan Perawat dengan Fuzzy Fitness Function. Tesis. Fak. MIPA jurusan Ilmu komputer UGM. Yogyakarta.

[12] Baker, Kenneth R, Introduction to Sequencing and Scheduling, John Wiley and Son Inc, Amerika, 1974

[13] Amar, S., 2012, Solving Long-Term Medical Trainee Scheduling. Tesis. Mechanical and Industrial Engineering Department, Engineering Faculty, UGM. Yogyakarta. 